\title{
Research on the Influence of E-sports News on Middle- Aged Audience Attitude
}

\author{
Siqi Liu ${ }^{1, \dagger}$,Zitong Shang ${ }^{1, \dagger}$, Yingzhuo Zheng ${ }^{1, *, \dagger}$ \\ ${ }^{1}$ Communication University of Zhejiang, Hangzhou, 310000, China \\ ${ }^{*}$ Corresponding author. Email: 184202244@stu.cuz.edu.cn \\ ${ }^{\dagger}$ These authors contributed equally.
}

\begin{abstract}
As E-sports is booming in China in recent years, E-sports news also appears in public in great numbers. Based on data analysis and literature review, it is clear that mainstream media's attitude towards E-sports has converted in the last few years, but do these news reports actually affect people's attitudes, especially the middle-aged? Compared with people from other age groups, they experienced the discourse transformation of E-sports in media and have sufficient ability to obtain new information, so their opinion means a great deal to the development of E-sports. To figure out this issue, we conducted a survey to explore the influence of E-sports news on middle-aged audiences' attitudes. Eventually, we find that news did change their attitude in the sort of ways. Still, it is not adequately objective and comprehensive, few middle-aged people in our research show enough knowledge about E-sports. And new media, as the crucial main battlefield of public opinion, is not used appropriately to propagandize E-sports. To make more people understand and embrace E-sports, the depiction of it should be multi-faceted. Hence audience will find the reality of the industry.
\end{abstract}

Keywords: E-sports, media, attitude, the middle-aged

\section{INTRODUCTION}

\subsection{Background}

\subsubsection{People's Daily on E-sports}

People's Daily, a famous newspaper, is the organ of the Central Committee of the Communist Party of China. On June 15, 1948, the newspaper was founded in Lizhuang, Pingshan County, Shijiazhuang City, Hebei Province. It was formed by the merger of Jinchaji Daily and Jinji Lu Yu People's Daily, which was the organ of the Central Bureau of North China, and also served as the organ of the Party Central Committee [1].

As the mouthpiece of the Party and the government, People's Daily actively publicizes the policies and propositions of the country, records the changes in Chinese society, and reports on the changes taking place in China. The direction of the People's Daily's coverage of China's E-sports industry also represents the government's attitude and views on E-sports. Based on the literature we reviewed and the data we searched, People's Daily's attitude towards E-sports is a visible transformation. E-sports is now illustrated as a sort of new industry, an inseparable part of the economy in
People's Daily, despite E-sports, or video games, once was critically denounced in the newspaper. It is an authoritative, serious, and comprehensive daily newspaper in China; therefore, its coverage greatly impacts people's mindset about E-sports.

\subsubsection{E-sports in China}

The term E-sports, or electronic sports, refers to the competitive gaming of video games. Normally it is multiple-player gaming between professional players. The player operates digital devices as sports equipment, and it's a competition of both mental and physical strength and of great spectatorship value [2]. In recent years, this sport is becoming a blooming industry. Many countries treat it as a profession and put effort into supporting its development. In the 2018 Jakarta Asian Games, E-sports games were held as performance events. On December 16, 2020, the Olympic Council of Asia (OCA) announced that E-sports would become an official event of the Asian Games and participate in the 2022 Hangzhou Asian Games. In China, on January 29, 2019, the Ministry of Human Resources and Social Security of the People's Republic of China (MOHRSS)issued a public notice announcing the launch of 15 new 
occupations, including E-sports player and E-sports operator.

However, there is a long-lasting misunderstanding of E-sports: "E-sports" equals "video games". From the 1980 s, when video games were first introduced to mainland China, the criticism and accusations never stopped, including "damaging health" "sex and violence content" "addictive", video games were viewed as a sort of dreadful monster, and gamers were viewed as idlers. Amid controversy, E-sports grew wildly. In the late 1990 s, when the Internet began to emerge in China, Internet café sprouted up on streets and alleys. Unlike arcade games and console games, the government regarded Internet café as a symbol of modernization and keeping pace with the trend. Thus, an increasing number of people_ particularly the youth_—was exposed to PC video games like StarCraft and Counter-Strike. In 2000, the first official StarCraft competition was held in Beijing, China, and the China E-sports Association was founded later [3].

Though commenced in the early 2000s, E-sports in China was still tepid in its own development. No country other than Korea has an integrated E-sports industry chain. In contrast, China has officially acknowledged that E-sports is a sport event, and many Chinese players had won prizes in international competitions. It was not until 2018 when Chinese team IG (Invictus Gaming) won the League of Legends S8 World Championship, social media really exploded and was filled with the news of IG, though many people at that time did not know what "IG" or "League of Legends" means. In 2019, some colleges and universities established E-sports-related majors [4], E-sports players, and event operators were officially acknowledged as occupations. The 2020 League of Legends World Championship S10 finals were held in Shanghai during the Covid-19 pandemic.

\subsubsection{Why Middle aged?}

Firstly, most young people have a supportive attitude toward E-sports. They care more about the novel and exciting experience brought by E-sports than the negative effects of E-sports, so the attitude change we are going to study is not obviously reflected in the young group. Secondly, older people are less receptive to information and have less access to news, and most of them do not know or have never heard of E-sports, so they were not selected as the target group for this study.

Compared with the young and old groups, middleaged people (specifically people from 30-59 years old) have a richer social experience. Their views on things are influenced by the media, society, policies, economy, and many other aspects. Many middle-aged people have children who can access E-sports or video games, and parents are often worried that video games would affect their children's studies or health. However, with the development of the E-sports industry, more and more young people are getting involved and working in Esports-related jobs, and such social trends also influence middle-aged people's views on E-sports. Besides, as the internet industry growing dynamically in China, most middle-aged people can use various medias independently to get information and learn more fresh news. Therefore, middle-aged people were chosen as the target group for the study, and questionnaires were conducted.

\subsection{Literature Review}

In E-sports news studies, Fan explored the impact of E-sports news on audience attitudes, claiming that Esports news attention does not directly affect the audience's cognition and emotional attitude but indirectly affects the audience's attitude by directly affecting their understanding of E-sports [5]. He \& Cao collected and examined the video game news reports from 1981-2017 of People's Daily, discussed the discourse transition of official media, identifying media discourse as not only a field in which multiple meanings compete with each other, but also a cycle in which the actors negotiate with each other [6]. Hong also examined the E-sports news from 1978-2018 of People's Daily, probed the complex media "mirror" of E-sports based on the historical context of reality [7]. According to Pan Jiawei, the attraction of E-sports lies in its interactivity and sense of achievement. In his article on the analysis of the current situation of E-sports communication in China under the $5 \mathrm{~W}$ communication model, he points out that mainstream media popularizes the concept of E-sports to the general public, which helps audiences understand more about E-sports. This means that there is a greater need for communicators to give full play to the media's agenda-setting role and guide audiences from the cognitive level [8]. Likewise, by using the " $5 \mathrm{~W}$ " analysis method, Cheng Yi analyzed the effect of E-sports culture in Chinese society and found that insufficient communication channels, generalized entertainment content, and public stereotypes about E-sports all had a negative impact on the communication effect. She also suggested that establishing an authoritative E-sports system and changing the mainstream social consciousness can promote the recognition of E-sports culture and its development [9]. And by analyzing the framework of the reports, it is also possible to study them in more detail in multiple directions, such as reporting topics, genres, presentation forms, and tendencies. Through this form of analysis, Yu Yi analyzed the reports of three newspapers, People's Daily, China Culture Daily, and China Computer Daily, and investigated their influence on the image construction of E-sports. Through his research, he found that Chinese media coverage of Esports suffered from a lack of depth of content, labeling of reports, and a lack of player discourse, which have led 
to the deficiency of scientific perception of E-sports in society [10].

There are also many studies focusing on the media image of E-sports. As Sha \& Du mentioned in their work, "E-sports culture is the integration of game culture, sports culture and media culture. Due to the virtuality, innovation, science and technology, and hyperspace of its projects, E-sports culture has produced a cultural image that is completely opposite to other traditional sports" [11]. Therefore, it is necessary to investigate the image of E-sports in China. Zhou probed the media representation of E-sports clubs on social platforms [12], Ma studied the change of mainstream media image of E-sports. Through his analysis, he found that 2008 became a key time point due to the financial crisis. Before 2008, media reports stigmatized the construct of E-sports, and after 2008, the media had a positive attitude toward the economic benefits brought by the E-sports industry. Ma raises the argument that the "transition of E-sports media image is a gimmick, but the real driver of the media is complex business logic". It's a tripartite cooperation of the media, government, and commercial capital [13]. He researched into media presentation of E-sports players, the paper suggests that E-sports players were portrayed as dream pursuers, strengthening the identity of "competitive performance", the contradiction between virtual and reality, and the marginalized "problem youth", and there are economic, political and cultural factors behind it, it is an incorporation of mainstream culture, resulting in the absence of a voice from E-sports players themselves. The difference between E-sports and online games lies in the fact that E-sports itself has certain antagonism consistent with the nature of sports. By strengthening the "competitive" character, E-sports is justified and distinguished from online games [14]. Using the League of Legends and the NBA as examples, Li Hailin compares the communication models of E-sports events and traditional sports events. $\mathrm{He}$ argues that the similarities between the two are that both the producers and the distributors of the events are becoming increasingly first-party and that the most significant difference between the content of E-sports events and traditional sports events is the omission of the athletes from the communication process, meaning that the images of the events are much more visible than the athletes [15].

In addition, many scholars researched "Internet addiction" and the panic towards video games. Some argue that it is a reflection of people's anxiety during a social transformation period. In "Just Like the Qing Empire" — Internet Addiction, MMOGs, and Moral Crisis in Contemporary China by Alex Golub \& Kate Lingley, the panic towards video games and "internet addiction" mirrors the sensitivity and vulnerability of China when it tries to integrate itself into the global system, The former moral order was tumbling, and social relations were being "medicalized", the rise of fashionable consumerism and new media was tempting but unfathomable, the family structure changed and created a dilemma for parenting, etc. [16]. Their work provides a relatively comprehensive analysis of why we were afraid of "E-opium". Shi, in his work, proposed that people were actually afraid of the same thing -- they want to "restore the model of state-led social control" and thus "quell all the 'dangers of modernity' that have been created in the process of dramatic social transformation." Further, he illustrates that as the game industry itself evolving, "self-dependent innovation" as the government's slogan and the transfer of social discourse power, the resurgence of the panic is nearly impossible [17].

From a global perspective, Marcella Szablewicz portrays live E-sports events in China as "representational" and live audience as ideological construct, nationalism and ideology are displayed in the industry [18]. Micaela Furrer introduced diplomacy analysis in China's E-sports, pointing out that there are still underlying contradictions in China's diplomacy, but "it will be interesting to see the direction in which China will move regarding E-sports, and if it will be able to hold its title as number one much longer in such a rapidly growing industry" [19].

These studies and theories above help us understand some background information in advance. However, there still remain some research gaps. We found that the research on audience attitudes in the past is too broad, with no research on audience attitudes specific to the middle-aged group, who experienced a great social and life transformation, and their opinions on E-sports really matter.

Through this study, we hope to find out if the official media's E-sports coverages really affect the attitude of middle-aged people towards E-sports. This will be used to analyze the image construction of E-sports in Chinese society. More importantly, it can bring implications for the dissemination of E-sports culture and its development. This study will use questionnaires to examine the changing image of E-sports in Chinese mainstream media and its impact on the attitudes of the middle-aged towards E-sports.

\section{METHODOLOGY}

To get a more insightful recognition of the attitude towards E-sports of middle-aged people under media influence, we conducted a survey based on Fan's work [5]. Aimed at people from 30-59, electronic questionnaires were distributed online to collect necessary data.

The whole questionnaire is made up of 7 parts. The first part is demographic variables, including sex, age group, living location, education background, occupation, marital status, children's situation. The second part is 
identification, Question 8: "Would you like to read news reports about E-sports?" is to understand the subjective attitude of the respondents; Question 9, "Have you ever read E-sports news?" is a questionnaire panel for screening respondents. If no, Questions 4, 5, and 14 will be skipped. Question 10 is to understand the channels through which the respondents are exposed to E-sports news. The third part is the survey of the respondents' attention to E-sports news. Inspired by the literature, four questions are set to determine the respondents' attention to E-sports news. The fourth part focuses on the media effect of E-sports news, including 2 single-choice questions and a multiple-choice question. The fifth part is questioning the respondents' understanding of E-sports, including 4 questions.

The sixth part is the survey on the cognitive attitude, emotional attitude of the respondents to E-sports, including 4 questions. The last part investigates the audience's views on E-sports news, including three questions.

From August 11 to August 14, questionnaires were distributed through the Weibo platform, one of China's biggest social media platforms. A total of 83 questionnaires were returned, including 0 blank questionnaires, 5 invalid questionnaires, and 78 valid questionnaires.

\section{RESULTS}

A total of 83 questionnaires were returned, of which 5 were invalid, and 78 were valid, representing a completion rate of 0.94 . Here are the personal statistics of the survey respondents.

Among the valid questionnaires, 25 were male, and 53 were female, with a male to female ratio of about $1: 2.12$. Second, $34.62 \%$ of the questionnaire respondents were from the $30-39$ age group, $47.44 \%$ were from the 40-49 age group, and the remaining $17.95 \%$ were from the 50-59 age group. In addition, more than half of the survey respondents are educated at the university level and above. Of the total number of respondents, 73 already had children, and another 5 did not.

50 of those surveyed had seen news stories about Esports, while the remaining 28 had not. We then investigated the level of interest in E-sports news coverage among the middle-aged groups. The table below shows the channels through which the middleaged group obtains news related to E-sports.
Table 1. Channel to access E-sports news reports

\begin{tabular}{|c|c|c|}
\hline Options & $\begin{array}{l}\text { Number of } \\
\text { people }\end{array}$ & Proportion \\
\hline $\begin{array}{l}\text { Traditional media } \\
\text { (Radio, TV, Newspaper, } \\
\text { etc.) }\end{array}$ & 11 & $22 \%$ \\
\hline $\begin{array}{l}\text { New media } \\
\text { (WeChat, TikTok, etc.) }\end{array}$ & 37 & $74 \%$ \\
\hline Other channels & 2 & $4 \%$ \\
\hline
\end{tabular}

In the section "To what extent do you follow E-sports news stories", $70 \%$ of respondents said if they come across E-sports-related news stories, they will browse them in detail.

Then, we chose to find out if the audience had some negative stereotypes about E-sports.

Table 2. Do you consider E-sports as "E-heroin"?

\begin{tabular}{lll}
\hline Options & Subtotal & Proportion \\
\hline I've never thought so. & 26 & $52 \%$ \\
I've always thought so. & 9 & $18 \%$ \\
I didn't think so, but I do now & 7 & $14 \%$ \\
because of E-sports journalism. & \\
I used to think so, but I don't & 8 & $16 \%$ \\
$\begin{array}{l}\text { anymore because of E-sports } \\
\text { journalism. }\end{array}$
\end{tabular}

It is worth noting that $86 \%$ of those who completed the questionnaire felt that E-sports news coverage had converted their attitudes to varying degrees. Of the options for changing attitudes, respondents mainly changed their basic perceptions of E-sports.

We then conducted a survey on the level of knowledge of E-sports among the respondents. Firstly, the survey results showed that $43.59 \%$ of the people already knew what E-sports was before filling out the questionnaire. Secondly, $70.51 \%$ of the respondents did not know that E-sports was the 99th official sport recognized by the General Administration of Sports of China. In answer to the question of the difference between E-sports and video games, more than $68 \%$ of the respondents already knew what the difference was. Finally, nearly $85 \%$ of the survey respondents could not list E-sports players or E-sports teams.

Next, we surveyed the attitude of middle-aged people towards E-sports. More than $55 \%$ of the survey respondents thought that E-sports were interesting. Also, over $40 \%$ of the respondents thought E-sports was a sport that could improve one's overall quality. Still, over $60 \%$ of the respondents chose the neutral or negative option in 
response to the question of whether the development of E-sports would help the development of China's sports industry. The final question was whether E-sports should be promoted and reported like traditional sports, almost $40 \%$ of the respondents answered with a positive attitude.

Finally, we surveyed respondents' attitudes towards E-sports news coverage. The data showed that $64.11 \%$ of respondents thought media coverage helps the public understand E-sports as a sport. 82\% of respondents thought media coverage would help E-sports be accepted by people of all ages and walks of life.

\section{DISCUSSION}

\subsection{Make the most of new media}

The questionnaire survey found that $74 \%$ of the respondents got E-sports-related information through new media platforms. With the development of information technology and the popularity of the Internet, more and more new media platforms have come into people's lives and occupy an irreplaceable position. Compared with "old" media such as traditional newspapers and TV, new media platforms like Weibo, WeChat and Tiktok are welcomed by people because of their fast information update, searching convenience, and loose time and space restrictions on information access. As the E-sports industry blooms in China, increasing news, short videos, and web dramas about E-sports appear on new media platforms. Even if middle-aged people do not deliberately search for the content, the algorithm will distribute it to their screen.

The short video platform represented by TikTok, in which the video posted is short in length and massive in information, makes the information obtained by the audience present a fragmented effect, which causes the audience to have one-sided information, for example, most respondents in the questionnaire survey know the difference between E-sports and video games, but they do not know that E-sports is the 99th official sport recognized by the Chinese General Administration of Sports. Before the survey, we found out that many middle-aged people have zero knowledge about E-sports (some of them are even very well-educated), they only know that their children play "Arena of Valor" and "PUBG" on their smartphone, that's all they understand about this term, so we offered enough background information of E-sports before they filled out the questionnaire. Therefore, when reporting E-sportsrelated content, to optimize the merits of new media to make content more "middle-aged friendly", it requires the media should not only combine the different characteristics of new media platforms, for instance, 1) using short videos, H5, AR technology to provide an immersive reading experience; 2) be familiar with the feature of various social media platforms, intentionally exert appropriate reporting style, and promote the information to the targeted audience, but also deliver some fundamental concepts and background knowledge of E-sports, by which people would understand E-sports deeper and more comprehensively since our result shows that they are willing to carefully read the text when coming across the E-sports news.

\subsection{The cliché of reporting}

In the questionnaire, $86 \%$ of the middle-aged people said that media coverage transformed their attitudes toward E-sports. Their exposure to E-sports-related coverage was positively correlated with their attitudes toward E-sports coverage. This suggests that the more middle-aged people read reports about E-sports, the more positive their attitude towards it. As an emerging industry, E-sports plays a huge role in promoting social and economic development, urban culture construction, and the development of new professions. Thus, the development of E-sports-related industries and the positive influence they bring to society also make the media's attitude toward E-sports coverage vary from negative to positive. The survey also reflects that the conversion in media coverage has led to a change in the attitude of middle-aged people towards E-sports. Esports and video games were lumped together in early media discourses and given the name "electronic heroin". The media's propaganda also focused on aspects that are harmful to young people's physical and mental health, detrimental to study. Hence, most people's impression of E-sports is negative and uninformed. $82 \%$ of the respondents in the survey believe that media coverage has helped E-sports to be accepted by people of all ages and walks of life, which suggests the importance of media coverage in enhancing the social acceptance of Esports.

Most of the current official media's coverage of Esports in China is about industry, economy, competition, [7]. However, more than $60 \%$ of the respondents in the survey still have a neutral or negative attitude towards the development of the industry, and many of them cannot name a player or a representative team. It is really worth considering that while media coverage has tried to convince the audience that E-sports is not "electronic heroin", it has not displayed a true understanding of the industry and its effect on society. This might prove that middle-aged people have not fully understood the industry and the people behind them (their recognition of E-sports players may remain unchanged for the sensational news reports in the past, which is showcased in the survey, many convert their opinion and treat Esports as "E-heroin" after reading the news coverage), few influential media coverages show the real face of Esports and its practitioners[14], they do not "showcase" the drudgery of practicing of E-sports players, the price they paid for this career. Therefore, to break the stereotype of E-sports, the media should promote the 
positive impact of E-sports and also the individuals behind the industry. An objective and comprehensive perspective of reporting is needed. Positive and effective media campaigns will boost the E-sports industry to grow more healthily in China as it changes people's attitudes.

\section{CONCLUSION}

By surveying whether the media coverage influenced middle-aged people's attitude towards E-sports, we found that most of them obtain such news from new media platforms and hold a positive attitude toward Esports and E-sports news. However, they do not fully understand this industry and its function in culture, economy or other aspects in China.

Even though in the survey, most of them admit Esports news reports has changed their attitude at some level, it is really worth noting that there is still a part of the sample that have not heard of E-sports or claim that the news coverage did not change their negative attitude towards E-sports, some even regard E-sports as "Eheroin" after reading the news. It is then essential to raise the concern that, in an era where information technology is booming, public policy is stimulating the development of E-sports, some people are still feeling doubtful and repugnant about this sport and industry. Hence, we suggest that media, especially official media like People's Daily, should firstly optimize the communication edge of new media, whether in the production process or distribution process, play the leading role in the media transformation. As the party's mouthpiece and the government, a crucial responsibility is to act as a guide when new things are emerging. Next, when doing E-sports coverages, it is essential to reveal the true face of this industry. Tempting prize money and economy stimulation are just the tip of the iceberg of Esports. Players training painstakingly to win the competition, team managers carefully operating the team, which, in fact, are the reality of the industry, these aspects are not displayed in mainstream media discourse. By illustrating different angles of E-sports, audiences are able to gain a more insightful understanding of the industry and get rid of the stereotype, they need stories and people that they can relate to. Thus, there is more possibility for them to embrace E-sports, along with more possibility for E-sports to develop steadily.

\section{REFERENCES}

[1] Baidu Encyclopaedia, People's Daily profile, https://baike.baidu.com/item/\%E4\%BA\%BA\%E6 $\% \mathrm{~B} 0 \% 91 \% \mathrm{E} 6 \% 97 \% \mathrm{~A} 5 \% \mathrm{E} 6 \% 8 \mathrm{~A} \% \mathrm{~A} 5 / 706569$ ?fr= aladdin

[2] Baidu Encyclopaedia, E-sports profile, https://baike.baidu.com/item/\%E7\%94\%B5\%E5\% $\mathrm{AD} \% 90 \% \mathrm{E} 7 \% \mathrm{AB} \% 9 \mathrm{E} \% \mathrm{E} 6 \% 8 \mathrm{~A} \% 80 / 190403$ ?fro mtitle $=\% \mathrm{E} 7 \% 94 \% \mathrm{~B} 5 \% \mathrm{E} 7 \% \mathrm{AB} \% 9 \mathrm{E} \&$ fromid $=110$ 0890\&fr=aladdin $\# 5 \_$.

[3] Lu Zhouxiang, From E-Heroin to E-sports: The Development of Competitive Gaming in China, The International Journal of the History of Sport, 2017.

[4] Xinhua Net

Client. https://baijiahao.baidu.com/s?id=16463303439737 $14768 \& w f r=$ spider $\&$ for $=$ pc.

[5] Fan Ruiling, Research on the influence of E-sports News on Audience Attitude, Jinan University, 2019.

[6] He Wei and Cao Shule, From E-heroin to Created in China: Discourse Change of Digital Game Coverage in People's Daily from 1981 to 2017, Chinese Journal of Journalism \& Communication, 2018.

[7] Hong Jianping, Entertainment, Education and Industry: The Mirror Image of E-sports in Mainstream Media_—Focusing on People's Daily (1978 - 2018), Journal of Chengdu Sport University, 2018.

[8] Pan Jiawei, Analysis, and research on the current situation of E-sports communication in China under the $5 \mathrm{~W}$ communication model [J]. Sports Vision, 2020.

[9] Cheng Yi, Analysis of factors limiting the spread of E-sports culture in China, Media observer, 2020.

[10] Yu Yi, Research on the image construction of online games in Chinese newspapers from the perspective of Framing Theory, Wuhan University of Technology, 2020.

[11] Sha Ruiyi and Du Youjun, Internal loss and construction of E-sports cultural image from the perspective of communication, Sports Journalism and Communication Branch, 2019.

[12] Zhou Yujie, Media image presentation of E-sports club on social platforms -- Take 2018 iG E-sports Club Weibo as an example, Sports World, 2019.

[13] Ma Zaiyuan, The change of mainstream media image of E-sports: focusing on People's Daily (1990-2018), Hainan University, 2020.

[14] He Zhaoning, Media Presentation Research of the E-sports Players_ - A Case Study of the People's Daily, Jinan University, 2017.

[15] Li Hailin, "Comparative study on the communication mode of E-sports events and traditional sports events - taking League of Legends events and NBA events as an example, East West South North, 2020. 
[16] Alex Golub and Kate Lingley, "Just Like the Qing Empire" — Internet Addiction, MMOGs, and Moral Crisis in Contemporary China, Games and Culture, 2008.

[17] Shi Chang, The end of panic: From "E-heroin" to Esports, Cultural Study, 2018.

[18] Marcella Szablewicz, A Realm of Mere Representation? "Live" E-sports Spectacles and the Crafting of China's Digital Gaming Image, Games and Culture, 2015.

[19] Micaela Furrer, E-sports Diplomacy in China, 2020. 